\title{
¿POR QUÉ BIOÉTICA Y DERECHO?
}

\author{
María Casado González*
}

Resumen: La Bioética tiende al reconocimiento de la pluralidad de opciones morales presentes en las sociedades actuales, propugnando la necesidad de establecer mínimos acuerdos. Los procedimientos que permitan decisiones consensuales tienen una importancia fundamental. Si no hay acuerdo, el Derecho deberá establecer los límites de lo permitido; de ahí deriva la estrecha relación entre Bioética y Derecho, entendido como norma de conducta que emana de la voluntad de todos.

Unir las nociones de Bioética y Derecho es importante, no para juridificar a la primera, sino para entender los valores constitucionales y los «principios generales de las naciones civilizadas» como acuerdo mínimo: a la luz de la Declaración de Derechos Humanos y de las demás declaraciones internacionales y convenios que forman parte de nuestro acervo común. Los Derechos Humanos constituyen a la vez la base jurídica y el mínimo ético irrenunciable sobre los cuales se asientan las sociedades democráticas.

Palabras clave: Bioética, derecho, derechos humanos, tecnologías genéticas, genoma

\section{¿WHY BIOETHICS AND LAW?}

\begin{abstract}
Bioethics tends to recognize the plurality of moral options present in today's societies, impeling the need to establish minimum consents. The proceedings that will allow consensual decisions have fundamental importance. If there is no agreement, legislation should establish the allowable limits; therefrom derives the close relationship between Bioethics and Law, understood as a code of conduct emanating from the collective will.

It is important to connect the notions of Bioethics and Law, not to juristify the first one, but to understand the constitutional values and the "general principles of civilized nations" as a minimum agreement: in the light of the Declaration of Human Rights and the other International Declarations and Conventions that form part of our common inheritance. Human Rights are both the juridical basis and the minimum ethical consensus essential for democratic societies that cannot be waive.
\end{abstract}

Key Words: Bioethics, law, human rights, gene technologies, genome

\section{PORQUE BIOÉTICA E DIREITO?}

Resumo: A Bioética acata o reconhecimento da pluralidade de opções morais presente nas sociedades atuais propugnando a necessidade de encontrar acordos mínimos. Os procedimentos que permitam decisões consensuais têm importância fundamental. Caso não haja acordo, o direito deverá estabelecer os limites do permitido, o que torna presente a estreita relação entre Bioética e Direito, entendido como norma de conduta que emana da vontade de todos.

Unir Bioética e Direito é fundamental, não para juridificar a bioética, mas para entender os valores constitucionais e os “princípios gerais das nações civilizadas" como mínimo acordo à luz da Declaração de Direitos Humanos e de todas Declarações Internacionais e Convênios que fazem parte do acervo da humanidade. Os Direitos Humanos são, por sua vez, a base jurídica e o mínimo ético irrenunciável sobre os quais se amparam as sociedades democráticas.

Palavras chave: Bioética, direito, direitos humanos, tecnologias genéticas, genoma

\footnotetext{
* Profesora Titular de Filosofía del Derecho, Moral y Política. Directora del Centro de Investigación «Observatorio de Bioética y Derecho». Directora del Master de Bioética y Derecho, Universidad de Barcelona, España

Correspondencia: mcasado@eco.ub.es
} 


\section{Introducción}

Hace ya más de tres lustros comencé a plantear que una concepción fecunda de la Bioética requería entender la nueva disciplina de una manera más amplia de lo que se estaba haciendo -en general, pero más especialmente en mi país-. Que era necesario considerarla como algo más que una reflexión de carácter moral sobre los problemas que suscitan las aplicaciones biomédicas, y que era preciso adoptar una visión global e interdisciplinar a propósito de las cuestiones que nos plantean las biotecnologías actualmente.

Desde mi punto de vista -entonces claramente minoritario- era necesario adoptar un enfoque que englobase planteamientos éticojurídicos y que también considerase los de carácter político, subyacentes a las decisiones que se adoptan. Tal postura suscitó entonces reticencias -cuando no clara oposición- entre las filas de los eticistas y los teólogos que consideraron que alguien ajeno se trataba de apropiar de lo que era competencia exclusiva suya. Y se percibió por algunos como un desembarco de los juristas en un terreno en el que los éticos -en especial los procedentes del campo de la ética médica- habían conseguido un protagonismo largamente deseado tras un período en que la incidencia social de la labor de los filósofos había sido escasa (la biomedicina había salvado a la ética ¿recuerdan?)

Hoy este planteamiento de tribus cerradas ha sido felizmente superado y la necesidad de contemplar las implicaciones éticas, jurídicas, sociales y políticas de la biotecnología es generalmente aceptada ya que representan las diversas caras de un prisma y de unos planteamientos que hemos dado en llamar bioéticos. A ello ha colaborado en gran manera el hecho de que en los programas de investigación en biotecnología y biomedicina de la Unión Europea hubiese un apartado específico -que se conocía como ELSI- que financiase estudios de las implicaciones éticas, jurídicas y sociales de los nuevos descubrimientos y de sus aplicaciones; también en el Proyecto Genoma Humano se han dotado partidas específicas para este tipo de análisis. Tanto es así, que se suele poner de relieve que nunca antes se había dedicado tantos fondos a estas cuestiones y que, pese a ello, no se han encontrado respuestas unívocas y definitivas para los problemas; aunque, eso sí, se ha racionalizado su planteamiento y se ha mejorado las metodologías que se proponen para su tratamiento.

Actualmente, la Bioética ha devenido en una disciplina interdisciplinar. Su aportación a la reflexión del s. XXI se predica como fundamental y en ella participan disciplinas diversas para aportar sus conocimientos, puntos de vista y bagaje profesional, a la construcción conjunta de pautas que nos permitan tratar los problemas que las biotecnologías nos plantean. Y que a todos nos conciernen en tanto que seres humanos, individualmente, y en tanto que constituimos una sociedad interrelacionada y plural, que comparte espacio.

En todo caso si quedaban reticencias a esta juridificación de la Bioética, la aprobación del Convenio de Derechos Humanos y Biomedicina ha venido a traer, claramente, las cuestiones a un modelo de reflexión que concibe los Derechos Humanos como el marco en que los problemas deben ser analizados; considerándolos como el mínimo común, jurídico y ético, en que se tiene que apoyar la toma de decisiones en las sociedades plurales. Así ha sucedido desde su aprobación por el Comité de Ministros del Consejo de Europa, en el 97, hasta su entrada en vigor en los distintos países (en España el instrumento de ratificación se publicó en el Boletín Oficial del Estado del 20 de octubre del 99 y entró en vigor el 1 de enero de 2000). Como es sabido, se trata de un Convenio de origen regional, pero cuyas aspiraciones son más 
amplias, pues está abierto a cuantos estados deseen firmarlo, independientemente de que procedan de otros ámbitos geográficos.

Así pues, desde que se cuenta con un convenio específico para la protección y promoción de los Derechos Humanos ante las cuestiones que les afectan desde el campo de la biología y la biomedicina, la ligazón entre Bioética y Derecho podría considerarse que no requiere de mayor argumentación. Pese a ello, parece conveniente un análisis de la cuestión que intente contextualizar y explicar la necesidad de tal enfoque.

\section{La relación entre Bioética y Derecho}

En las sociedades que se rigen según un modelo democrático de convivencia, hay que convenir en que los problemas que afectan a la sociedad en su conjunto deben ser decididos por todos los ciudadanos, tras un debate suficientemente informado, y no sólo por sectores minoritarios, frecuentemente en condiciones de opacidad. Esta exigencia es especialmente perentoria cuando las decisiones que deben tomarse afectan a toda la sociedad, incluyendo las generaciones presentes y las futuras. Como se ha mencionado, los problemas derivados de los descubrimientos científicos y de los adelantos biotecnológicos son, precisamente, de este carácter, que reclama respuesta tanto de los individuos como de la comunidad.

Los enormes avances científicos han supuesto un cambio en la sociedad de carácter cuantitativo y cualitativo de una magnitud tal que han obligado a revisar los planteamientos individuales y colectivos en torno a numerosas cuestiones que afectan al ser humano.

El actual progreso de la medicina y la biología suscita grandes esperanzas, a la vez que ocasiona dilemas para el hombre común y para los especialistas, sean médicos, biólogos, científicos, filósofos o juristas. La primera y brutal toma de conciencia colectiva de los problemas éticos de la medicina data de la Segunda Guerra Mundial con las revelaciones de los experimentos médicos del nazismo. El Código de Nuremberg, de 1947, constituye el primer conjunto de reglas internacionales que relaciona ética médica y Derechos Humanos. Tras él las Declaraciones de la Asociación Médica Mundial en Helsinki (1964), en Tokio (1975) y en Manila (1980), incidieron en el principio fundamental de que hombres y mujeres no pueden ser un simple objeto para la ciencia.

A partir de los años setenta, las relaciones entre seres humanos, ciencias y medicina sufrieron un cambio importante ya que, junto a la tradicional tarea curativa, el progreso biotecnológico supuso la oportunidad de intervenir en los procesos vitales fundamentales. La misma posibilidad de realizar un diagnóstico genético de enfermedades que aún no se han manifestado o la de aplicar terapias génicas en el tratamiento de determinados tipos de cáncer, muestra una forma de medicina y de biología radicalmente nueva que implica un cambio de tal naturaleza que obliga a poner en cuestión los parámetros de valoración tradicionalmente utilizados. Esto ha llevado a cuestionar los fines mismos de la medicina y la reflexión sobre los cambios producidos ha dado lugar a valiosas aportaciones.

La conferencia de Asilomar ilustra acerca de las preocupaciones de la comunidad científica. Ante la posibilidad de manipular la molécula que contiene información genética o ADN -descubrimiento que dio un enorme impulso a la biología molecular-, se produjo una considerable inquietud ante los posibles riesgos derivados de la transferencia de genes. En estas circunstancias, los propios científicos se pronunciaron a favor de establecer una moratoria que detuviera temporalmente la manipulación genética experimental y la 
obtención de organismos genéticamente modificados. Aunque actualmente dicha moratoria no rige, se han establecido reglas internacionales restrictivas, como las directivas comunitarias de diciembre de 1990 referentes al control de los riesgos de dicha manipulación. El progreso científico es ambivalente, no sólo en el sentido de que puede ser positivo o negativo, sino porque cualquier enfoque bien intencionado puede devenir perverso.

En este contexto surgió la Bioética como una nueva disciplina que, desde un enfoque plural, pusiese en relación el conocimiento del mundo biológico con la formación de actitudes y políticas encaminadas a conseguir el bien social. Como decía V. Potter, la Bioética es "el conocimiento de cómo usar el conocimiento", el puente entre ciencias y humanidades. Es fácil constatar, empíricamente, que las materias tratadas por la Bioética tienen su reflejo inmediato en el ámbito jurídico, tanto en el ámbito legislativo y jurisprudencial como desde el punto de vista del interés práctico de quienes trabajan en estos campos, cuyas nuevas implicaciones y responsabilidades resultan -cuanto menosproblemáticas. Existen, además, móviles económicos y extraordinarios intereses implicados.

Por otra parte, las medidas de control son complicadas en cuanto a la implantación y, más aún, en cuanto a su posterior seguimiento. No se trata de frenar el progreso, lo que sería irreal por otra parte, pero se deben considerar los límites de la investigación hasta que los riesgos sean evaluados y controlados. Para que sea eficaz, la preocupación bioética debe estar presente desde el principio y no limitándose a juzgar desde fuera sobre la bondad de los descubrimientos realizados y su uso. Eso sería demasiado tarde, puesto que los distintos poderes políticos y económicos ya se habrían apoderado de los resultados de la ciencia y los mass-media habrían difundido la prometedora seducción de las mágicas novedades. El auge de la discusión filosófica y jurídica sobre el alcance del principio de precaución puede confirmar lo que aquí quiere plantearse.

Los problemas de la Bioética deben ser debatidos por la sociedad en su conjunto antes de que sean adoptadas soluciones normativas, sobre las que, en una sociedad democrática y plural, es preciso lograr consenso. Un consenso que, en cuestiones que atañen a los valores individuales y colectivos en forma tan especial, resulta difícil conseguir. Por ello, conviene centrar la búsqueda del compromiso en la elaboración de unas reglas del juego aceptables para la mayoría de los ciudadanos independientemente de sus opciones ideológicas. Es el rol de las primeras comisiones y comités de Bioética que surgen en diferentes países. Estas comisiones son un magnífico lugar para el debate informado y para el encuentro entre los distintos puntos de vista. Además, constituyen una ayuda muy valiosa para los poderes públicos en tanto que pueden suministrar pautas para la adopción de políticas y de regulaciones acordes con las informaciones científicas y el sentir de la sociedad a la que se dirigen dichas innovaciones -y que, asimismo, las financia-. Las comisiones de ética de diverso alcance -desde las hospitalarias y las de investigación a las creadas para cuestiones $a d$ hoc o las nacionales, regionales y de cualquier alcance-, deben constituirse en co-laboratorios en los que se pongan en común los distintos enfoques y acervos profesionales y culturales para elaborar pautas de conducta -temporales y revisables- que permitan abordar los problemas comunes.

Así, para la reflexión bioética resulta importante el proceso de elaboración y el análisis de las normas que deben regir la acción en lo que se refiere a la intervención técnica del hombre sobre su propia vida; esto implica la necesidad de llegar a un acuerdo sobre el estilo de vida por el que se opta y, en consecuencia, del tipo de sociedad que 
queremos construir. Todo esto concierne a los poderes públicos ya que se ponen en juego cuestiones fundamentales, no sólo por la importancia de la biomedicina para la salud de la población, sino por la evidente necesidad de no quedar al margen de los descubrimientos científicos y sus beneficios, cuya incidencia social y económica es de gran trascendencia. Es preciso que los parlamentos y los gobiernos tomen en consideración cuál es la situación real en lo que se refiere a la investigación, a su desarrollo industrial, a los costos de la salud, a todo un cúmulo de problemas que van más allá de los aspectos puramente científicos, económicos e incluso sociales. El establecimiento de determinadas políticas supone la elección de un determinado modelo de sociedad que excluye otros, lo cual no debe ser resuelto sin reflexión y debate previos.

El término Bioética, aunque consolidado, presenta inconvenientes diversos, entre otros, los derivados de que los problemas que engloba son más bien político-jurídicos que éticos. La cuestión clave se centra en si hay que regular o no las posibilidades que nos brindan las tecnologías "bio" y, de hacerlo, en qué sentido. Se trata de problemas que, al no tener una respuesta social unívoca, desembocan en una demanda de legislación y eso deviene una típica cuestión de axiología jurídica: cuáles son los valores que debemos proteger y cómo debe hacerse. Ante la posibilidad de intervenir en los procesos biológicos hay discrepancias sociales que generan conflictos, y son éstos los que requieren de la intervención del Derecho para establecer los límites a la libertad de actuación individual.

\section{Bioética, Derecho y pluralidad de opciones morales}

Un aspecto central de la Bioética está, precisamente, en el reconocimiento de la pluralidad de opciones morales que caracteriza a las sociedades actuales y en propugnar la necesidad de establecer un mínimo marco de acuerdo por medio del cual individuos pertenecientes a "comunidades morales" diversas puedan considerarse ligados por una estructura común que permita la resolución de los conflictos con el suficiente grado de acuerdo. La elaboración de unos procedimientos de toma de decisiones en las que todos los implicados puedan participar, supone un paso de importancia fundamental. Pero en último extremo, si no hay acuerdo, el Derecho deberá establecer los límites de lo permitido; de ahí deriva la estrecha relación entre la Bioética y el Derecho -entendido como norma de conducta que emana de la voluntad de todos-.

Las normas jurídicas poseen una evidente relación con las morales, aunque no dependan de la ética para su configuración, y a lo largo de los siglos el análisis de estas relaciones ha sido una cuestión central del pensamiento filosófico-jurídico. Nuestro planteamiento parte de la constatación del pluralismo moral de la sociedad y del hecho de que ese pluralismo no sólo es un hecho sino que es un valor constitucionalmente protegido. Pero, al mismo tiempo, estamos en contra del escepticismo en los valores, en el sentido de considerar que es posible argumentar racionalmente en ética y de que pueden esgrimirse "buenas razones" a favor de las opciones que se elijan. Frente a las posturas de relativismo extremo, la posición de la que aquí partimos implica la posibilidad de dilucidar racionalmente si los juicios morales que sostenemos son correctos. Frente a las posturas que preconizan la existencia de verdades absolutas e incontrovertibles, se propone que cualquier juicio moral esté sujeto a la discusión y a la crítica racional.

Los planteamientos, individuales y sociales pueden, por otra parte, partir de la confianza y la fe en el "progreso bienhechor" o de la desconfianza radical ante la "ciencia 
deshumanizada". Frecuentemente se plantean las cuestiones como conflictos de actitudes globales; es fácil verlo al tratar sobre la eutanasia, el aborto, o la consideración de los límites de la ciencia. Pero esos conflictos "radicales" también se dan en otros campos: en las opciones políticas, por ejemplo, y hemos aprendido a compatibilizarlas ¡quizás tras siglos! Estas visiones de conflictos de absolutos, que sostienen importantes pensadores y que están presentes en determinados sectores de opinión, no son un buen punto de partida para analizar las cuestiones y para aprender a compatibilizarlas, cosa que hemos de hacer necesariamente. Quizás sea en este tipo de situaciones en las que mejor se pone a prueba la tolerancia de las personas y de las sociedades: la tolerancia como táctica no es lo mismo que la tolerancia como actitud activa.

Pueden surgir las discrepancias que se deriven del mismo sentido en que se conciben las palabras clave, aquéllas cuya definición nos coloca en un incómodo compromiso: persona, dignidad, vida..., lo que supone un problema inicial para la Bioética. Lo primero es, pues, elucidar su sentido y divulgar las preocupaciones ante los ciudadanos: las cuestiones de la Bioética son cuestiones ¡políticas!

Esto plantea el problema del acuerdo moral, del consenso en ética, y de su valor. ¿Existe o no desacuerdo en los principios morales? En todo caso ¿pueden coexistir visiones diversas? La discusión entre las posiciones universalistas y las que hacen hincapié en la diversidad y el pluralismo es sobradamente conocida y de la más plena actualidad. En mi opinión, el principal problema estriba en que la ética y el discurso moral "civil" o laico, no tienen aún construidas respuestas a los problemas de la Bioética mientras que, por el contrario, la teología sí tiene respuestas dogmáticas que cuentan con el aval de siglos de utilización sin fisuras. Lo cual nos lleva de nuevo a los Derechos Humanos y a la posibilidad de acuerdo sobre los mismos en el nivel teórico de reconocimiento y de su fundamentación, sin entrar en el de su violación o respeto.

\section{Un ejemplo para el análisis: las implicaciones de las nuevas tecnologías genéticas}

Las nuevas tecnologías genéticas están ocasionando cambios de gran impacto social, moral y jurídico. Constituyen un buen campo para intentar validar el enfoque propuesto, ya que sus enormes posibilidades generan actitudes ambivalentes que requieren de la realización de un debate social informado y del establecimiento de normas éticas, sociales y jurídicas que permitan maximizar sus beneficios y minimizar sus riesgos, lo que constituye un buen ejercicio democrático.

Las noticias sobre los descubrimientos realizados en torno al genoma humano han generado expectativas inmensas para la mejora de la salud y han venido deparándonos cambios de gran impacto social, moral y jurídico, ya que sus posibilidades han sido percibidas por los ciudadanos como ambivalentes. No obstante, conviene distinguir entre los innegables conflictos que se plantean y que pueden afectar a importantes derechos ya reconocidos y el miedo a la ciencia, que subyace detrás de algunos fantasmas del inconsciente colectivo tan gratos a la ciencia-ficción. Así, se pone de manifiesto cuando, tras cada nueva posibilidad de las nuevas tecnologías genéticas -sobre todo en sus aplicaciones sanitarias-, suelen alzarse voces reclamando prohibición (el caso de la clonación resulta paradigmático). Ello hace patente que las nuevas tecnologías genéticas reclaman la realización de un debate social informado en el que participen los diversos sectores implicados: investigadores, médicos, humanistas, políticos, informadores... La racionalidad en la discusión reclama una información previa que deben suministrar los científicos -que conocen los auténticos problemas, puesto que trabajan materialmente con las tecnologías que cuestionamos- y transmitir los medios de comunicación, a través de los cuales la conoce la generalidad de las personas de nuestra sociedad. A partir de los datos, la reflexión debe hacerse en común, 
evaluando los riesgos para determinar qué cosas son las que se deben limitar, con qué criterios se establecen las limitaciones y quiénes han de ser los que las establezcan. Sólo así, tras valorar las distintas cuestiones en juego, será posible tomar decisiones sobre las repercusiones de descubrimientos que a todos nos afectan.

\section{Regular las nuevas técnicas:}

Hay que señalar que Genoma y Derecho son conceptos necesariamente unidos, ya que el ordenamiento jurídico debe cumplir su función de control y organización social. En general, las aplicaciones biomédicas de las nuevas tecnologías no suelen plantear el problema de ser ilícitas sino más bien de cuáles son los límites a su licitud. Ante ellas, el Derecho se debate entre una actitud no intervencionista (que deja al mundo de la investigación en un área de "no Derecho", siguiendo los criterios marcados por la conciencia del investigador o de su grupo) y una postura controladora, que emerge cuando la preocupación social así lo aconseja. Actualmente existe abundante regulación sobre las tecnologías genéticas, y precisamente nuestro país fue de los primeros en normativizar el uso de las mismas dentro de una actitud pro tecnológica que en aquellos momentos era símbolo de aperturismo. Las normas existentes forman un abanico que comprende desde las de carácter administrativo (las primeras en ser utilizadas, pues en temas de salud es frecuente la intervención de los poderes públicos), a las civiles y penales. Todas ellas insertas en el marco del respeto a los derechos fundamentales fijado por la Constitución y las leyes que los desarrollan y en un contexto internacional que busca la armonización normativa.

Concretamente en España, están reguladas las técnicas de reproducción asistida, la donación y utilización de fetos y embriones, la utilización, liberación y comercialización de organismos modificados genéticamente con el fin de prevenir los riesgos para la salud humana y el medio ambiente, y ciertas conductas referidas a la manipulación genética se sancionan en el código penal. Además, la Unión Europea ha elaborado numerosas directivas sobre organismos modificados genéticamente, riesgos laborales, protección de datos, patentes, etc. También los organismos internacionales han forjado textos como el Convenio sobre Diversidad Biológica de Río de Janeiro, auspiciado por las Naciones Unidas, o la Declaración de los Derechos de las Generaciones Futuras y la Declaración Universal sobre el Genoma Humano, de la UNESCO, que pretenden completar la Declaración Universal de Derechos Humanos. Y, como se ha repetido anteriormente, contamos con el Convenio para la Protección de los Derechos Humanos y la Dignidad del Ser Humano con respecto a las aplicaciones de la Biología y la Medicina, elaborado por el Consejo de Europa como organismo específicamente encargado de su protección y promoción de los Derechos Humanos en el ámbito europeo, pero abierto a la firma de cuantos países lo deseen.

Esta relación, no exhaustiva, permite entrever que, aunque exista abundante regulación, aún queda mucho por hacer. Como, por ejemplo, en numerosos países, dictar leyes que regulen las bases de datos genéticos actualmente existentes para garantizar el adecuado uso de las mismas. Para calcular lo ingente de la tarea, basta pensar en que la mera información obtenida del Proyecto Genoma puede afectar a derechos como la intimidad, la no-discriminación, la autonomía, el pluralismo, la dignidad de la persona o la libertad de investigación. Sirva de muestra la huella genética cuya obtención puede interesar a efectos de mera identificación, así como en procesos civiles y penales, pero que aporta datos sensibles que pueden afectar a la salud y ser usados por terceros en la contratación laboral o en los seguros. Es necesario tener presente que el conocimiento de los individuos que la 
información genética hoy disponible proporciona, puede ser utilizado en los más diversos ámbitos y con los más diversos fines. Nadie duda que identificar con certeza a los individuos es útil para el Estado, pero también puede serlo para los ciudadanos. Así sucede con la identificación en procedimientos civiles y penales (las pruebas de paternidad o los análisis de muestras halladas en el lugar de un crimen, por ejemplo) que, de hecho, implica una garantía para la población, aunque también genera miedo a un mundo orwelliano en el que nos hayamos convertido en seres totalmente "transparentes", desprovistos de intimidad y privacidad. Igualmente preocupa a los ciudadanos la utilización de esos datos por compañías aseguradoras, en los procesos de contratación o en la concesión de hipotecas. Por otra parte, mas allá de la mera identificación en el terreno de la salud, los avances en el estudio de las patologías genéticas permiten saber sus causas moleculares y proporcionan nuevas posibilidades de diagnóstico, que repercutirán tanto en la prevención de la enfermedad como en los tratamientos que puedan ofrecerse. Aun en mayor medida sucede así con la ingeniería genética, la clonación, la terapia génica o la medicina preventiva que han llegado a poner en cuestión los tradicionales objetivos de la medicina. Conocer la dotación genética individual permitirá diseñar nuevas terapias personalizadas que se ajustarán a cada caso, disminuyendo los efectos nocivos y potenciando la eficacia de los nuevos tratamientos, cuyas posibilidades irán aumentando a medida que se conozcan nuevas funciones de los genes y su relación con las enfermedades. Todo esto tiene incontestables ventajas para la salud pública, pero puede llevar aparejado inconvenientes para los individuos $y$ ser el origen de nuevas formas de discriminación.

Consecuentemente, el Derecho debe estar atento a los cambios científicos tratando de controlar los riesgos potenciales de los mismos, sin ser un obstáculo a la innovación, sino actuando como elemento de racionalización y de garantía. Sin perder de vista la necesidad de que sus normas estén dotadas de la temporalidad limitada que requiere una materia en continua evolución y basadas en el consenso que, idealmente, debe seguir al debate social informado que tanto se preconiza.

\section{Reflexionar sobre ellas:}

No conviene olvidar el papel que la reflexión moral y el debate social desempeñan en este campo. Ya se ha señalado que las tecnologías genéticas resultan ambivalentes, pues su uso es susceptible de generar grandes beneficios para la humanidad, pero también riesgos derivables de un mal uso cuyas consecuencias son imprevisibles y que pueden afectar no sólo a quienes las emplean sino al resto de la humanidad, e incluso a las generaciones futuras. Inconvenientes y ventajas que conducen a que las biotecnologías se perciban como una espada de doble filo y a que los ciudadanos tengan grandes miedos y grandes esperanzas sobre sus posibilidades. Estas ambivalencias se reflejan en el debate bioético y resultan patentes en los medios de comunicación y en la opinión pública. Es habitual preconizar un principio general de precaución con el cual no cabe sino estar de acuerdo, siempre que no nos haga adoptar la postura de "prohibir por si acaso", a veces subyacente a visiones del futuro que resultan un tanto apocalípticas. Así, se suele insistir en la necesidad de establecer una regulación que prevenga y frene los posibles abusos. Pero, como se ha indicado más arriba, normativa ya existe tanto en el ámbito nacional como internacional; lo que ocurre es que la mera existencia de normas es insuficiente. Regular desde arriba no basta; es necesaria una información rigurosa y un debate previo sobre las implicaciones de la biotecnología que permita llegar a establecer acuerdos, aunque sean parciales y revisables.

En este sentido, es constatable que cada vez que se descubren nuevas aplicaciones de las 
tecnologías genéticas, sobre todo si afectan al origen de la vida, se alzan voces que reclaman pararlo todo, "desinventarlo" si fuere posible. Aseguran que estamos suplantando a la divinidad y que nuestras pretensiones y nuestro orgullo serán castigados. La cosa no es de ahora, ni mucho menos. La corriente que desconfía del conocimiento y de las novedades ha existido siempre: desde Adán y Eva en el Paraíso ("si coméis del árbol de la ciencia seréis como dioses") a Ícaro, o Perseo, o Fausto... Pese a ello, el ser humano siempre ha querido saber para controlar los procesos de la naturaleza, que se consideraban inamovibles mientras no se conocía cómo se desarrollaban. No obstante, ya hace tiempo que sabemos que si sembramos en determinadas condiciones obtenemos mejores cosechas que si dejamos que el trigo salga solo. Hace tiempo que intentamos controlar las condiciones naturales: ponemos calefacción en invierno y aire acondicionado en verano, preferimos viajar en coche o en avión a hacerlo andando, o en burro. Hablar por teléfono, usar Internet, o grabarnos en video, permite estar en varios sitios a la vez -incluso después de muertos podemos hacernos presentes y dejar mensajes-, lo que proporciona posibilidades de intervención y control antes sólo reservadas a la divina ubicuidad.

Pero la primera vez asusta, nos preocupa salir de lo que siempre se ha hecho, de lo que siempre ha sido así. La falacia naturalista -"es así, luego debe ser así"... y seguir siendo asíes grata a la naturaleza humana que considera la costumbre como necesidad. A los niños para tranquilizarlos les contamos siempre los mismos cuentos, de la misma manera, con las mismas palabras. Repetir sosiega: es un recurso literario y un uso habitual de las religiones (de los mantras al rosario) Sin embargo, ¿qué nos hace adultos si no es tomar las propias decisiones y dirigir nuestra propia vida? Las nuevas tecnologías genéticas nos permiten intervenir en procesos que antes estaban fuera de nuestro alcance -en manos del azar- y que por ello considerábamos como naturales. Ahora podemos canalizarlos. $\mathrm{Y}$ esto genera responsabilidad por la orientación que demos a las transformaciones: ¿alimentos para todos? ¿diagnósticos y medicina preventiva? ¿fármacos a la carta generalizados? $\mathrm{O}$, por el contrario, ¿ejércitos de humanoides esclavizados? ¿selección exhaustiva y discriminatoria para acceder a los puestos de trabajo o a un seguro? ¿datos genéticos, personales y sensibles, de libre acceso? ¿ciudadanos transparentes? La decisión no corresponde a las tecnologías genéticas. Dependiendo del nivel al que estemos considerando las cosas: se tratará de una decisión política y social, o de una decisión ética.

Los seres humanos somos "por naturaleza" culturales -es decir, adaptadores del medio- y está en nuestras manos elegir y actuar moralmente. Cómo ejercer la libertad es algo que se debe decidir responsablemente y esa decisión se debe construir socialmente. Pero hablar de deber es hablar de normas. De restricciones que nos imponemos a nosotros mismos y cuya procedencia hay que justificar; porque la libertad es el principio y el punto de partida, aunque pueda ser limitada si existen razones para ello. Podemos escoger qué dirección queremos darle a nuestra vida, esa será una decisión moral -autónoma-; y también podemos establecer qué dirección queremos darle a nuestra sociedad, pero ésta tendrá que ser una decisión colectiva - política y jurídicasi queremos que sea vinculante.

\section{Conclusión}

Constituye, pues, un buen recurso la utilización de las normas jurídicas: como remedio y como punto de partida. Por ello es útil unir las nociones de Bioética y Derecho. No para juridificar la Bioética en el sentido legalista de la expresión, sino para entender los valores constitucionales y los "principios generales de las naciones civilizadas" como 
acuerdo mínimo: a la luz de la Declaración de Derechos del Hombre y de las demás declaraciones internacionales y convenios que forman parte de nuestro acervo común.

En las últimas décadas, la biología y la medicina han avanzado más que cualquier otra ciencia en el resto de la historia. Sus descubrimientos producen mayor conmoción a la humanidad y suscitan mayores interrogantes que el hallazgo del fuego en su momento. Corresponde precisamente a las actuales generaciones el establecer por adelantado un código común basado en un consenso que vaya más allá de escuelas y creencias. La reflexión del conjunto de la sociedad debe permitir acortar al mínimo el tiempo de asimilación y aceptación de los cambios y del control de sus consecuencias, teniendo en cuenta que más vale prevenir que corregir, lo cual en este terreno puede llegar a ser del todo imposible. Ésta es una tarea colectiva que debe basarse en el respeto al otro (autonomía), entendido como un respeto solidario (justicia).

Los Derechos Humanos constituyen a la vez las bases jurídicas y el mínimo ético irrenunciable sobre los que se asientan las sociedades democráticas. Esta afirmación es central para establecer las pautas de conductas asumibles por todos, independientemente de la fundamentación de que se parta. Las nuevas circunstancias -que derivan de la repercusión de los nuevos descubrimientos en las viejas concepciones de la vida, de la muerte y de lo que significa el ser humano-, acarrean cambios en el pensamiento ético y tienen enormes implicaciones en el ámbito de la política y en el del Derecho.

La coexistencia de valores y principios en que se basa toda sociedad democrática tiene que ser asumida también en Bioética: por eso la propuesta de una "Bioética flexible" parece ser una buena manera de concebir esta nueva disciplina para el siglo XXI que se sustenta en los principios constitucionales y los Derechos Humanos, que la enmarcan y la dotan de contenido. Se trata de contar con marcos para el acuerdo, no con soluciones dogmáticas ni consensos generales vacíos de contenido real, asumibles por todos, pero que nada resuelven. Y estamos obligados a elegir sin la garantía a priori de que optamos por el mejor modelo de todos los posibles. No contar con certidumbres previas deja al ser humano más solo e inseguro, pero hay que estar dispuestos a resolver sin muletas y a asumir las consecuencias.

El buen funcionamiento del sistema democrático exige que los temas fundamentales del debate no sean decididos por grupos de expertos sino que todo el conjunto de la sociedad se enfrente con decisiones que antes estaban reservadas sólo a grupos minoritarios, al "destino" o a la divinidad. Lo quiera o no, la sociedad civil está involucrada en las decisiones y debe evitar caer en una nueva tecnocracia de expertos que, encerrados en las reglas de su tribu, dictamina sobre lo correcto y proporciona soluciones mágicas. La reflexión y la posterior normativización sobre las biotecnologías y sobre las aplicaciones biomédicas constituyen un ejercicio de democracia que debe apoyarse en el respeto a los Derechos Humanos reconocidos internacionalmente. Acogerse a estos criterios representa una guía fiable; el respeto y promoción de los Derechos Humanos son la mejor pauta a la hora de juzgar la bondad y maldad de las biotecnologías y las prácticas biomédicas. Ellos representan el consenso logrado en torno a cuáles son las exigencias de la dignidad humana.

La Bioética necesita de la reflexión ética previa y del debate ciudadano, pero, después, requiere decisiones político-jurídicas. 


\section{Bibliografía:}

Casado M. Bioética, Derecho y Sociedad. Madrid: Editorial Trotta; 1998.

Casado M. El Alzheimer: Problemas Éticos y Jurídicos. Valencia: Editorial Tirant lo Blanch; 2002.

Casado M, comp. Estudios de Bioética y Derecho. Valencia: Editorial Tirant lo Blanch; 2000.

Casado M, ed. Materiales de Bioética y Derecho. Barcelona: Editorial Cedecs; 1996.

Casado M, González Duarte R, eds. Los retos de la genética en el S. XXI: genética y bioética. Barcelona: Ediciones UB; 1999. 